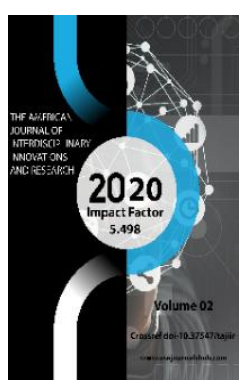

\title{
Modern Tendencies In The Ethnic Relations Of Kuramas
}

\author{
Laylo Kushmanova \\ Independent Researcher, History Institute of the Academy of Sciences of the Republic of \\ Uzbekistan, Tashkent, Uzbekistan
}

\begin{abstract}
Journal Website: http://usajournalshub.c om/index,php/tajiir

Copyright: Original content from this work may be used under the terms of the creative commons attributes 4.0 licence.
\end{abstract}

\section{ABSTRACT}

The article highlights the issues, such as Kurama ethnicity ( or "ethnic group of Kuramas"), which is involved in the Uzbek nation, its ethnic composition, the identity sense of the Kuramas in terms of unity of the people, the attitude to the Uzbek national unity and transformational processes. Corresponding issues are presented as material for ongoing scientific analysis based on field materials and, where appropriate, scientific and popular literature data. The core meaning of the term "kurama" is explined by the fact that this ethnic group is of the polycomponent. To be specific, it is feasable to promote the idea that the genetic composition of Kuramas has a common root with Karluk, Kipchak and Oguz ethnicities, since the period of Turkish commonality. Subsequently, after the end of the Turkish commonality and the formation of independent Turkic fraternal nations, the ethnic union of the Uzbek, Turkmen, Kyrgyz and Kazakh peoples began in Central Asia. In particular, the main core of the Uzbek nation began with the Karluk branch, while the Uyghur ethnos grew in the same process with the Uzbek ethnic genesis, and the subsequent stages of development in the border areas were independent. However, the bond of historical ties between the two branches has not been ripped up.

The article also analyses the issues of genetic memory of Kuramin residents of different villages along the streams of mountain and rivers. Thus, a survey conducted among the residents of Lashkarak Sai shows that the older generation practically began to forget the tribal origins of not only individual families, but also the entire group of residents of the compact community of the village. As for the inhabitants of Ertashsay, which originates from the Karakush peak, dividing the Tianshan mountain ranges into Chatkal and Kurama, they partly associate themselves with the traditional 92 Uzbek tribes. However, this information of Ertashsay residents is contraindicated for data on the genetic mixing of the Kuramis, consisting of Uzbek-Kazakh-Kyrgyz components. 
Our observations on the formation of the names of certain groups of Kuramins are interesting. Thus, the inhabitants of a number of villages, who have retained the memory of family ties in the past, are now known by various nicknames given to them from other villages. For example, Ezma top (chatty), Kal topi (bald), Zhanghirok topi (bells), Pulat topi (steelworkers), Toq topi (fed), etc. In addition, some groups of Kuraminians got their names from their place of residence: Kuramin residents Kurboz, Badrangi, Chelenovul, Ajir ovul, Samguron ovul, Guldirama soy, Kara kishlak, Soyogzi, etc.

In general, in the ethno-cultural situation of the Kuramin people, there is a gradual tendency to smooth out the previously stable traditional forms of life, social relations and purely Kuramin rituals and customs, which merge with the general Uzbek ones, since the Kuramin people mostly identify themselves as Uzbeks.

\section{KEYWORDS}

Kurama, identity, Uzbeks, ethnic unity, ethnicity, ethnic component, transformation, Uzbekization, Ertosh, Lashkarak

\section{INTRODUCTION}

The Kurama mountain range and the Akhangaron river valley, Akhangaron-Piskent, Urta Chirchik, partly Buka and Akkurgan districts are the most densely populated areas of the Kurama ethnic group (the phrase "Kurama ethnicity" is also sometimes appropriate [1]), which is becoming more and more integrated into the Uzbek nation.

According to some sources, the formational history of the Kurama ethnic group has ancient roots. Nevertheless, some informants put forward the idea that the history of the participation of ethnic components in the formation of the Kuramas are closely associated with the formational period of the Kazakh Khanate and the invasion of the Dzungars and Kalmyks.

The core meaning of the term "kurama" is explined by the fact that this ethnic group is of the polycomponent. To be specific, it is feasable to promote the idea that the genetic composition of Kuramas has a common root with Karluk, Kipchak and Oguz ethnicities, since the period of Turkish commonality.
Subsequently, after the end of the Turkish commonality and the formation of independent Turkic fraternal nations, the ethnic union of the Uzbek, Turkmen, Kyrgyz and Kazakh peoples began in Central Asia. In particular, the main core of the Uzbek nation began with the Karluk branch, while the Uyghur ethnos grew in the same process with the Uzbek ethnic genesis, and the subsequent stages of development in the border areas were independent. However, the bond of historical ties between the two branches hasnot been ripped up.

\section{THE MAIN RESULTS AND FINDINGS}

Baised opinions about the Kipchak dialect categories of the Uzbek nation in science today. It is said that the Kipchak dialect was added to the Uzbek people only in the 16th century. If this problem is considered on the basis of the proportions of excess or deficiency of the Mongol feature in the anthropological image, according to the anthropologist T.Q. Khodjaev's calculations, $10-20 \%$ of the peoples of Central Asia had 
Mongol elements in the $3 r d$ and 2nd centuries $B C$. It is not a sudden occurrence that in these centuries, the quantitative aspects of the Mongol feature in the local context were increasing or maintaining a certain coefficient drag [2].

Materials of scientific literature and oral information on this issue confirm the participation of Kazakh and Kyrgyz components in the composition of Kuramas. There are a number of examples of this. For example, Anorboy Nodirov, a retired teacher, says that the father of the Nurboy ethnicity was Kazakh, but in the second and third generations, the first ethnogenetic link was forgotten and the psychology of Uzbekism came to the fore [3].

According to the considerations of the informant, Usmonali Mirzaliev in Ertosh village, Kuramas contain kazakh and kyrgyz components, but this genetic element has lost its status at an early stage [4].

The representatives of the Mirzabeks kinsman located along the Lashkarak gorge confirms that, the marital relations of the residents of this area have largely remained inside the local circle. However, over the last quarter of a century, this tradition has been gradually eroding, meaning that today's Lashkarak youth are increasingly marrying outside the region.

"Ashabo"-the tajik-speaking kinsman, who live in the upper reaches of the Lashkarak gorge, has never been involved in marriages with the Kuramas in the past, and even moved out overnight if one wanted to marry the kurama's daughters. However, in recent times, Ashabos also began to interfere with kuramas. This trend is particularly noticeable in the late twentieth and early twenty-first centuries, when border and trade relations between Tajikistan and Uzbekistan were relatively limited [5].
When the role of the kipchak dialect was significant in the ethnic composition of the kuramas, the tendency to pronounce the " $\mathrm{J}$ " sound in speech" was the leading one in the regional language situation. However, in recent years, in the context of the uzbek literary language, as well as in the context of school education, the active participation of the younger generation in social life, the tendency to pronounce the "J" sound in speech has been declining. However, it is felt that the tendency to pronounce the "J" sound in the speech of the older generation is preserved. The conclusion is that the linguistic situation of the Kurama ethnic group is increasingly shifting towards current literary language norms.

There are different opinions on the origin of the term "kurama". In particular, according to Anorboy Nodirov, kuramas were united by collecting them as an invitation to gather together when they were scattered everywhere. According to Abduqayum father in Ertosh, a population consisting of a genetic combination of different ethnic groups is called kurama "combined". In our opinion, this explanation is close to the truth [6].

Specific observations on the ethnic and social status of kuramas suggest that a clearly demarcated kinship system does not exist in practice. In this sense, the social concept of "kinsman", which is widely used among kuramas, is noteworthy. In particular, while some kinsmen start their pedigree from their fathers, some are explained by the nicknames used in relation to their team (kinsman). For example, Mirzabek kinsman in the Lashkarak village trace their family tree to Mirzabek Great Father and Utakul Dodkhoh, Korabek, Khudoynazar, Mirzarahim, Mirzakarim, Dodamat respectively. The Mirzabek kinsman in the Lashkarak village seem to have maintained a relatively endogamous relationship for a long time, turning the kinsman into a kinship system. Sometimes 
Mirzabek and Qurboz kinsmen take brides from abroad. The 92-years old Abdugaffor Kuziev's daughters-in-law are one from Karatash and the other from Karakhitay, and this is a sign of the couple's desire to have a genetic connection outside their own sphere. A similar exogamous attitude is observed in the family of Anorboy ota Nodirov. His youngest son, Alisher, was married to a girl named Umida from the village of Appartak. She is sart, by her father, and kurama by her mother.

Nodirov Anorboy's opinion also points to the first message about the kinsman, that nicknames played a role in their naming. For example, Ezma, Tokberdi, Pulat, Jangirak, Kal, Tentak and others [7].

Usmonali Mirzaliev from Ertosh said that the term sart was used as a nickname for one of the kinsmen, citing the fact that either the mother or the father of the family was a sart(the nomadic people used so-called term "Sart" for calling the native population, peasants and handicraftsmens of the city), that is, the settlers were shown to be uzbeks. There are also cases when some kinsman are named after the area where they live. For example, Abdukosim Akhmedov (1966) listed another series of kinsman associated with place names. These are Kurboz, Badrangi, Chelenovul, Ajir aul, Samguron aul, Guldirama soy, Kara kishlak, Soyogzi and others [8].

Another interesting piece of information came to light in a conversation with Ertosh people. They say that the kuramas came to Ertosh from Shahrukhiya, the confluence of the Ahangaron and Syrdarya rivers. The reason for their stay in Ertoshsay was that they called the place far from the village of Chinor as Borsa Kelmas. It was as if the five brothers had come to Ertosh and were sitting on the cap, but they could not return. This means that they went and did not return, and Ertoshsay got the name Borsa Kelmas. Here comes an idea. In other words, there seems to be some forgotten genetic link between the people of Chinar and Ertosh. However, the narrators did not point to this meaning.

\section{CONCLUSION}

Following the above comments, it is appropriate to make some comments on the ethnic list of the composition of the kurama population, which A. Khasanov, T. Mirzakulov, referring to Isomiddin Yormatov. The authors have correctly identified the general groups of the tribes, such as yapalok, samarchik, kochartop, boytop, kalmoq top, and mixed the names of common turkic tribes and clans such as jalair, uyshun, kerayit, argin, bolgali, pulot. On top of that, they added the concept of kuramas to the all-Turkic 92-line Uzbek lineage [9]. Such a view seems to ignore the existence of independent roots of the kurama ethnic group. On the one hand, the authors tried to overemphasize the position of the Kurama ethnic group. A similar attitude can be seen in the words of Usmonali Mirzaev in Ertosh. According to him, the Kuramas are associated with the Boysun kungirats and they are the main link of 92 Uzbek tribes. In this view, the position of the Kuramas is exaggerated. In fact, without discriminating against the Kurama ethnic group, it can be said that today this ethnic group is at the stage of intencivily assimilation into the titul uzbek nation.

\section{REFERENCES}

1. Yormatov I. Valley of Happiness. Tashkent: Navruz, 2012. -277 p.

2. T. K. Khodzhayov, G. A. Khodzhaeva. Mongoloidness of the population of Central Asia and its dynamics // Central Asian ethnographic collection. Issue IV 1. $M$.: Nauka, 2001. -p.31-46; Khodzhaev T.K., Askarov A.A., Buryakov Yu.F. New archaeological and anthropological materials for the ethnic history of the peoples of 
Central Asia and Kazakhstan. Common problems. Issue 1. Moscow: Nauka, 1990. - p.54-65.

3. Field records. Anorboy Nodirov. Verbal information. Mobile phone record (Ertosh village. July 28.18).

4. Field records. Usmonali Mirzaliev. Verbal information. Mobile phone record (Ertosh village. July 28.18).

5. Field records. Tashkent region, Lashkarak village. July, 2018.
6. Field records. Ertosh village. Mobile phone record from Anorboy Nodirov. 2018, July.

7. Field records. Lashkarak. August 1, 2018.

8. Hasanov A, Mirzaqulov T. Independence: history and destiny. Tashkent: Muharrir, 2010. -P.6-

9. The same work, p. 8-9. 